\title{
Catastrophic risk: social influences on insurance decisions
}

\author{
Michal W. Krawczyk ${ }^{1}$ - Stefan T. Trautmann',3 \\ Gijs van de Kuilen ${ }^{3}$
}

(c) The Author(s) 2016. This article is published with open access at Springerlink.com

\begin{abstract}
We study behavioral patterns of insurance demand for low-probability large-loss events (catastrophic losses). Individual patterns of belief formation and risk attitude that were suggested in the behavioral decisions literature emerge robustly in the current set of insurance choices. However, social comparison effects are less robust. We do not find any evidence for peer effects (through social-loss aversion or imitation) on insurance take-up. In contrast, we find support for the prediction that people underweight others' relevant information in their own decision making.
\end{abstract}

Keywords Insurance $\cdot$ Risk attitudes $\cdot$ Beliefs $\cdot$ Catastrophic risk

JEL Classification C91 · D81 - D83 · G22

We thank participants at the 2014 Experimental Finance Conference in Zurich, and the conference on "Large risks with low probabilities: perceptions and willingness to take preventive measures," Naleczow 2016, for helpful suggestions. The research was supported by the Polish National Science Centre Research Grant DEC-2012/04/A/HS6/0061.

$凶 \quad$ Stefan T. Trautmann trautmann@uni-hd.de

Michal W. Krawczyk

mkrawczyk@wne.uw.edu.pl

Gijs van de Kuilen

g.v.d.kuilen@uvt.nl

1 Faculty of Economic Sciences, University of Warsaw, 44/50 Długa, 00-241 Warsaw, Poland

2 Alfred-Weber-Institute for Economics, University of Heidelberg, Bergheimer Str. 58 (Room 01.029), 69115 Heidelberg, Germany

3 Department of Economics and CentER, Tilburg University, P.O. Box 90153, 5000LE Tilburg, The Netherlands 


\section{Introduction}

The economic consequences of catastrophic events have become more severe in recent years (IPCC 2012; Michel-Kerjan and Kunreuther 2011). On the one hand, it is believed that climate change leads to more variability and more extremity of weather events. On the other hand, migration to and capital accumulation in vulnerable areas have increased over time. To limit the negative consequences of catastrophic events, policies are required that reduce the vulnerability to catastrophic losses and redistribute or shift the exposure to risks to those who are willing and able to bear them. Governmentsponsored protection and insurance programs have already been installed in many countries, and will increasingly become important if weather events become more severe in the near future.

While the supply of affordable insurance and protection products is crucial, it has been observed that there may also be important problems on the demand side for these products. As Michel-Kerjan and Kunreuther (2011) discuss, take-up of catastrophic insurance, for example, flooding insurance, is surprisingly low. Inhabitants of vulnerable areas might be very hesitant to take up even subsidized insurance products. For example, only 40 percent of residents of the New Orleans parish had flood insurance when hurricane Katrina struck, despite support from the National Flood Insurance Program (Insurance Information Institute 2005). There is little agreement yet on why people do not have strong preferences for insuring catastrophic losses. Assuming that they are typically risk averse with respect to their financial outcomes, fair or even subsidized insurance products should be very attractive.

Some important observations have been made in the literature. Risk attitudes and risk perception for small probability events may be subject to significant biases and basic deviations from rationality principles (Botzen and Bergh 2009; Gallagher 2014; Schade et al. 2012; Viscusi and Zeckhauser 2006). The leading alternative theory of decision making under risk, cumulative prospect theory (Tversky and Kahneman 1992) proposes that individuals attach an overly large weight to unlikely but extreme events. In this case, the loss will be overweighted, which again strengthens willingness to insure. However, empirical regularities that gave rise to prospect theory were observed mostly in the case of decisions from description, i.e., when probabilities were explicitly provided in a numerical format. By contrast, when probabilities are only learned by observation or experience, individuals may be prone to the underestimation of low probabilities (Hertwig et al. 2004). In particular, a significant group of people may simply neglect small risks (Botzen and Bergh 2012), but at the same time, over-insure against high-probability low-cost risks (Browne et al. 2015).

An important dimension of risk perception and insurance choice concerns the social effects caused by the observation of other decision makers (Kunreuther et al. 2009). Using field data, Gallagher (2014) shows when a county is hit by a flood, residents in neighboring counties increase their insurance take-up. Friedl et al. (2014) argue that the simultaneous over-insurance for high-probability low-cost risk and under-insurance for low-probability high-cost risks is due to social comparison and correlated losses: typical low-probability natural risks are highly correlated across people in a region or neighborhood (e.g., flood insurance as in Browne et al. 2015) and typical highprobability risks are uncorrelated across people (e.g., bike theft as in Browne et al. 
2015). In the former case, social comparison does, therefore, not lead to the feelings of loss, because peers also lose, while in the latter case, the loss is felt more strongly.

In contrast to these findings, Viscusi and Zeckhauser (2015) have shown that people may in fact not learn much from informative experiences of other people in their social environment. Using field data on tap water contamination, they show that people's beliefs are not influenced by negative observations of their peers. In the context of low-probability loss events, such a neglect of others' information significantly delays the learning process about the risk.

The current paper builds on these findings. We observe that the aforementioned results derive from a set of studies that each used specific empirical and experimental setups and that it is not clear in how far these findings generalize across different situations. Studies based on field data as in Gallagher (2014), Viscusi and Zeckhauser (2015) or Browne et al. (2015) have high external validity for the type of catastrophic risk under investigation. However, they typically have less control over the underlying mechanisms. For example, it is not clear whether higher take up in neighboring counties after a flood is caused by higher demand by homeowners, or by stronger or more successful marketing effort from the side of the insurance companies. The strong influence of peers on insurance decisions found in some studies seems at odds with the neglect of peer information in the formation of expectations observed in others. ${ }^{1}$ In the context of small probability losses, we, therefore, investigate the robustness of these empirical patterns in one uniform catastrophic loss insurance setting: how do decision makers process probabilistic information in low-probability loss settings? What is the effect of peer outcomes on beliefs and insurance take-up? How are these effects moderated by the correlation of potential losses among people?

Low-probability events are especially difficult to study in the field. Moreover, it is not easy to identify causal effects of peers' behavior and experiences in nonexperimental settings (see the discussion in Viscusi and Zeckhauser 2015). Because people may self-select into vulnerable areas (Page et al. 2014), and because this selfselection may interact with insurance choices, few conclusions regarding the effect of exogenous policy changes can be drawn. We, therefore, conduct a controlled laboratory experiment to identify the causal effects of social information and risk correlation (across people) on risk perception and insurance take-up. Our findings can be summarized as follows. In line with the decision-from-experience literature and with the previous field studies on natural disaster risk perception, we find that people underestimate the likelihood of low-probability outcomes. At the same time, they behave risk averse, conditional on these probability estimates, and the resulting subjective expected losses. Moreover, we confirm non-experimental results by Viscusi and Zeckhauser (2015) showing that people seem to significantly discount relevant information available through other people's experiences. This is an important result, because in contrast to Viscusi and Zeckhauser's study, in our setup, the other person's outcomes are unambiguously relevant to the decision maker's beliefs. However, we do not find any evidence that insurance take-up is affected by the correlation of an individual's

\footnotetext{
1 It is clearly possible to have a utility function with a social reference point while at the same time having beliefs that neglect others' information. However, from a psychological perspective, it is at first sight surprising that social influences would be restricted to a certain dimension only.
} 
risk of losses with those faced by other participants (Friedl et al. 2014); neither do we find evidence for direct imitation of insurance behavior. We discuss possible reasons for this result. Our findings show that behavioral effects in individual decision making are robust and replicate across vastly different empirical setups, and thus form a good basis for economic policy intervention (World Bank 2015). Social effects seem less robust. More research is needed to establish how policy can benefit from considering these effects.

\section{Design and methodology}

\subsection{General setup}

In a two-stage setup, participants earned a substantial income of PLN80 ( €20) in the first stage of the experiment, and were exposed to an uncertain loss of this income in the second stage. The first stage consisted of reading and evaluating an academic paper unrelated to the current experiment. In the second stage, subjects had two tasks: they were asked to assess the uncertain probability of the loss and to make a decision whether or not to purchase insurance against this potential loss.

To study how subjects update information and incorporate these updates in their decisions, the second-stage loss-exposure task consisted of 40 decision-making periods. Between these periods, the subjects received treatment-specific information. However, there were no dynamic changes in the subjects' financial status across periods: each period involved a new exposure to the loss of the original PLN80 and a new insurance offer, irrespective of earlier losses or insurance costs. Exactly one of the 40 periods was selected at the end of the experiment to determine the monetary payments to a participant. This design thus assures that there are no interdependencies across periods, apart from the learning effects that are the focus of the current study.

In each period, subjects faced an uncertain chance of losing their PLN80 endowment that was randomly selected from the interval $(5 \%, 25 \%)$ : this probability was identical for all subjects in a group (defined in more detail below) and for all periods, but it differed across sessions. The true value of the probability was never disclosed to the subjects, but they were aware of the interval from which the probability was drawn. Keeping the probability constant over time allowed subjects to update their beliefs about the probability on the basis of the past experiences and observations. In each round, subjects first made a prediction of the true underlying probability of the loss. These predictions were incentivized: if the specific period and task were selected for payment, the subjects would receive PLN80 minus four times the absolute difference between their guess and the true probability. For example, if a subject predicted a probability of $15 \%$ given a true probability of $10 \%$, she would receive $80-4 \times \operatorname{abs}(15-10)=$ PLN60. Note that this is not a typical subjective probability elicitation task, which is often incentivized using proper scoring rules. In this case, the underlying probability answer was well defined, so that rule could be simplified. It was incentive-compatible for risk-neutral subjects, while (severe) risk aversion could draw subjects' prediction somewhat towards the middle of the interval (15\%).

The second task in each round was the insurance decision. Each subject was given six offers (prices) for a full-insurance contract against the loss. The prices were deter- 
mined by adding a random noise in the range $(-3,+3)$ to each of six deterministic values $6,11,16,22,31$, and $41 .^{2}$ These prices were selected on the basis of pilot tests to cover the possible range of values that subjects may hold for the insurance of PLN80 loss that occurs with a probability in the range $(5 \%, 25 \%)$. More specifically, the pilot showed that these prices were roughly sextiles of the distribution of willingness to pay when subjects had little information as to the probability of the loss beyond this baseline range. Prices were identical for all members in a group, but they were newly determined for each period. For each price, subjects had to indicate whether they wished to purchase insurance or not. If the respective period and task was selected for payment, one of these six decisions would subsequently be selected to determine insurance status and earnings.

The pricing method allows us to calculate the subjects' willingness to pay for insurance against a small probability loss. We observe for each subject her preference in six ordered choices between an uncertain loss of PLN80, and some smaller loss for sure. We define the subjects' willingness to pay (WTP) as the midpoint between the highest price for which the person purchases insurance and the lowest price for which she prefers the sure loss. ${ }^{3}$ For example, for a subject who chooses insurance for prices 8,11 , and 16 , but prefers to stay uninsured for prices 24,33 , and 43 , we calculate WTP of PLN20. This procedure appeared to be easier and less repetitive (due to the random variations in prices across periods) than a direct-matching elicitation of the WTP using a BDM mechanism or auction format.

\subsection{Treatments}

Subjects participated in the second-stage task in groups of five. The identity of other group members was unknown to each subject. At the end of each period, subjects received feedback regarding their own and other group members' choices and outcomes, depending on three treatment conditions discussed below. In addition, there were two treatment conditions that differed in the way the group members' losses were correlated. That is, the experiment implemented a 2 (risk correlation) $\times 3$ (information condition) treatment design that we explain in more detail next.

In the Uncorrelated Losses condition each subject's loss was independently randomized in each round. In the Correlated Losses condition, individual risks in a five-person group within each round were highly correlated. Specifically, we independently drew two loss events from the underlying probability distribution of the loss. For example, with a 0.2 probability of a loss, the situation loss/loss would emerge with probability 0.04 , the situation loss/no-loss would emerge with probability 0.16 , and the situation no-loss/no-loss would emerge with probability 0.64 . Then, each subject would be randomly assigned one of these two events. As a result, while each person has a 0.2 probability of loss, loss experiences are correlated across subjects. For example, with the above underlying 0.2 probability of loss, the probability that none of the five subjects experienced a loss becomes $0.8^{2}+0.2 \times 0.8 \times 2 \times 0.5^{5}=0.754$, compared to

\footnotetext{
2 The procedure made sure that the six offers were always monotonically increasing after the random noise had been added. Details on the procedure are given in the Appendix.

3 Note that here the WTP identifies the subject's certainty equivalent for the uncertain loss.
} 
only 0.328 in the case of Uncorrelated Losses. Subjects were only given verbal, informal description of their condition (the verbatim description is given in the Appendix).

The three information conditions varied as follows. In the Individual Information condition, at the end of each round, each subject would learn (1) which of the six insurance contract offers was drawn and could be relevant if this period was selected for monetary payment; (2) as a consequence, whether she was insured in this round or not; and (3) whether she suffered a loss in this round or not. Note that an insured loss would still be accounted as a loss experience on the information screen, because it provides relevant information on the uncertain loss probability, similar to the information content of covered losses outside the lab. In the Social Information: Loss condition, the subject would have all information as given in the Individual Information condition, and would additionally learn how many other members of the group experienced a loss event in this period. In the Social Information: Loss and Choice condition, the subject would have all information as given in the Social Information: Loss condition, and would additionally learn how many other members of the group were insured in this period. Again, insured losses were included as experienced losses, because they are informative on the uncertain loss probability (which was identical for all members of the group in all treatments).

Knowing each subject's history of observable past losses at any point in time and the uniform prior distribution of loss probabilities, we can calculate posterior distributions in every round using the Bayes formula. We approximate posteriors numerically (based on the simplifying assumption that the true underlying probability can only take a finite number of values uniformly spread between 0.05 and 0.25 ) and calculate their means. Subjects could have assessed these posterior probability estimates in principle themselves. To be sure, this would be a formidable task and it has long been claimed (Simon 1955) that people do not make good intuitive Bayesians. These values serve only as a benchmark in the current study.

\subsection{Lab details}

Sessions were run in November and December 2013 in the Laboratory of Experimental Economics, University of Warsaw. Participants were recruited from the local subject pool. Because of the nature of the first stage of the experiment, it was emphasized in the invitations that subjects had to be proficient in English and have some understanding of academic economics. However, the second stage of the experiment, as well as the instructions, were given in Polish language. A session would typically have four groups of five people. In each session, all groups were either in the Correlated Losses or all in the Uncorrelated Losses condition. In contrast, the information treatment conditions were varied within session. The experiment was computerized using the $z$-tree software (Fischbacher 2007). Sessions typically lasted almost two hours and subjects made nearly PLN70 on average.

\section{Results}

We structure the discussion of the findings along our research questions. We first discuss the effects for risk perception (Sect. 3.1), then the effects for risk attitudes 
(Sect. 3.2). In Sect. 3.3, we discuss the role of social comparison on beliefs and choices.

\subsection{Probability predictions}

We first assess participants' judgments of the ambiguous probability of the loss event and the consequences for their insurance choices. Figure 1 plots the difference between the estimated probability and the true probability across treatments and periods, averaged over subjects. Overall, there is clear evidence that people underestimate the likelihood of small probability losses. Aggregating for each participant over all periods, we find an overall significant underestimation of the true probabilities (Wilcoxon signrank test, $z=3.850, p<0.01$ ) ; however, when looking at the different conditions separately, this effect is significant only for the two treatments with social information (individual $p=0.183$; social-loss $p=0.005$; social-loss-choice: $p=0.018$ ). Interestingly, even over the time frame of 40 periods, there is no indication that people become more pessimistic (i.e., more realistic) over time, or that participants converge to the same beliefs (i.e., the quadratic deviation from the true loss probability across subjects does not diminish significantly over time). This is surprising, especially in the social treatments, as it becomes very likely that subjects encounter or observe loss

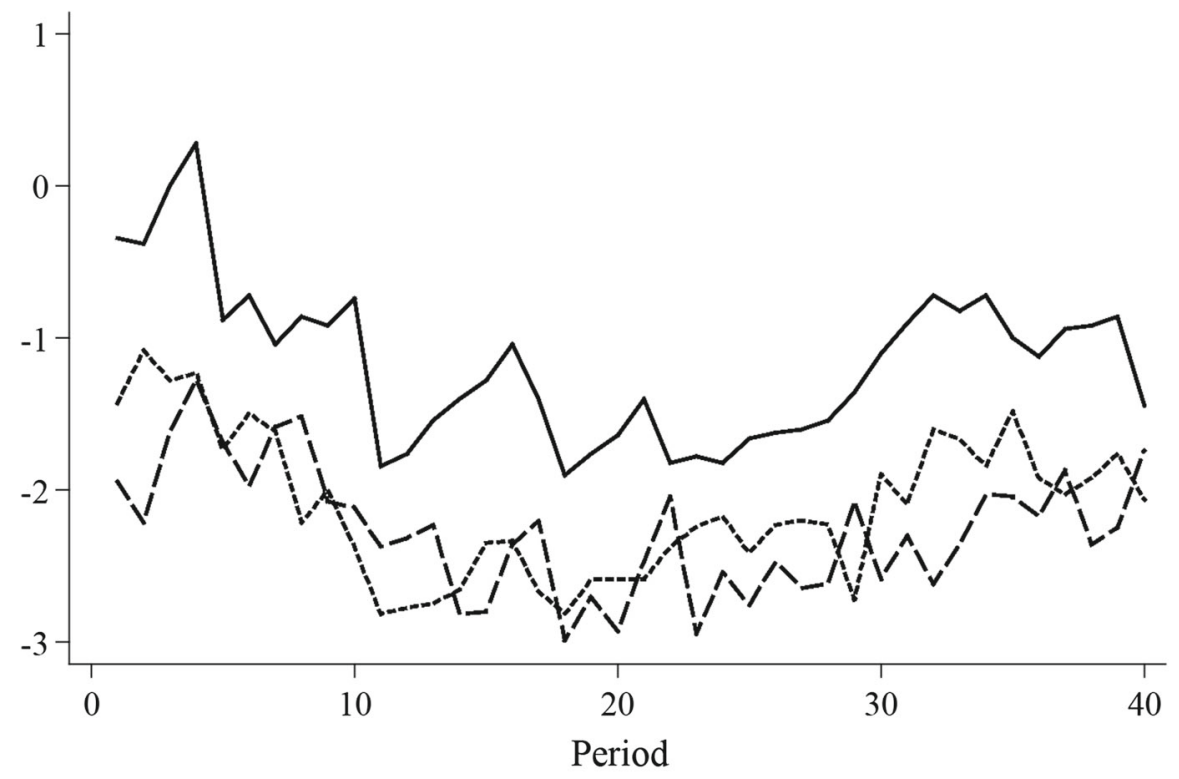

Fig. 1 Difference between estimated probability and true probability across treatments and periods (in prob. points). Notes: Positive numbers indicate overestimation; negative numbers indicate underestimation of the true probability 


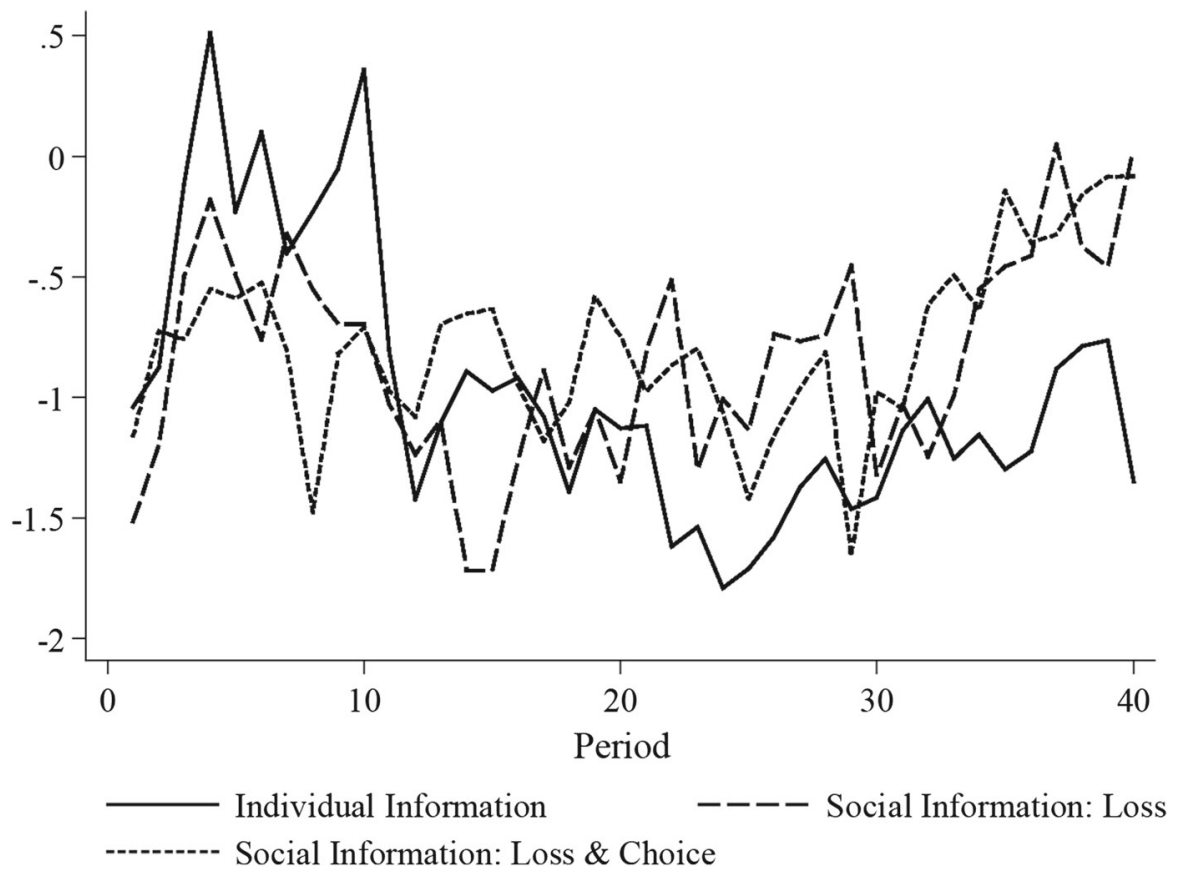

Fig. 2 Difference between estimated probability and Bayesian posterior probability across treatments and periods (in prob. points). Notes: Positive numbers indicate overestimation; negative numbers indicate underestimation of the true probability

events at some point, and in fact observe the same number of loss events within their group. That is, underestimation due to a pure sampling error, as well as variation across people, should become less severe over time. Interestingly, we thus do not find conservatism in the probability estimates, which would imply significant overestimation for low-probability events (Huck and Weizsäcker 2002; Trautmann and Kuilen 2015).

Figure 2 shows that essentially the same picture emerges if we define over/underestimation in terms of deviations from the mean of the Bayesian posterior distribution given observed history of losses. Again, subjects underestimate in all information conditions. This effect is strongly significant when pooled across all conditions ( $p=$ $0.003)$ and also for the individual information condition $(p=0.030)$, but not for the social conditions separately (social-loss $p=0.130$; social-loss-choice $p=0.104$ ). The temporal pattern is similar to Fig. 1. Thus, using the information actually observed by the subjects, we again find persistent underestimation of the small loss probability.

\subsection{Risk aversion}

On the basis of the participants' reported subjective probabilities of the loss event, we can calculate their individual-level subjective expected loss (denoted SEL), as it evolves over time. By comparing this value with the subjects' WTP for each period's insurance offer, we can assess their risk attitude in the domain of low-likelihood losses. We define our measure of risk aversion as the difference between the WTP and the 


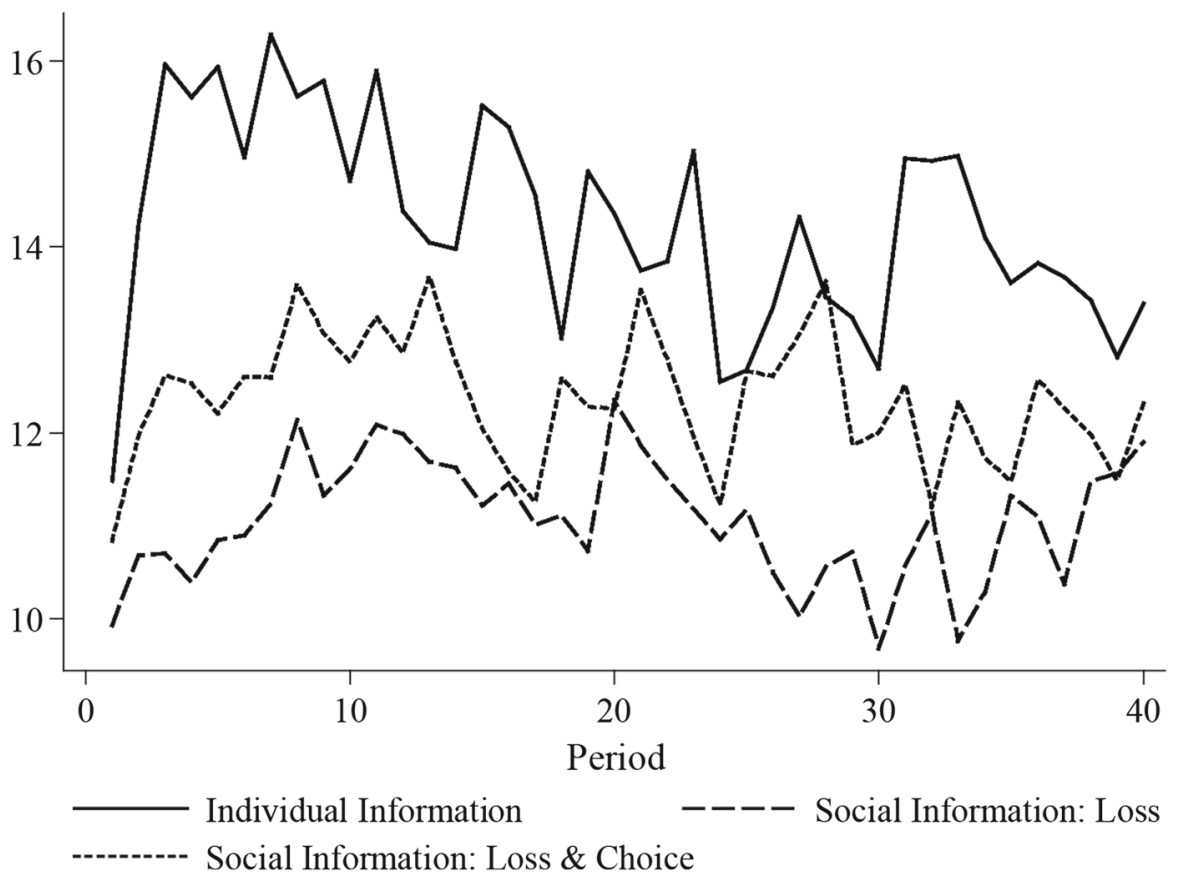

Fig. 3 Degree of risk aversion across treatments and periods (WTP-SEL). Notes: WTP willingness to pay to avoid loss; SEL subjective expected loss; Positive numbers indicate risk aversion; negative numbers indicate risk seeking. Based on individual-level subjective expected loss

SEL. Thus, positive values indicate risk aversion, and negative values indicate risk seeking. Figure 3 shows risk attitudes across treatments and periods, averaged over subjects.

In all treatments, subjects are on average risk averse in all periods. Indeed, the average degree of subjects' risk aversion across all periods is significantly larger than zero for all treatments (Wilcoxon sign-rank tests, $p \mathrm{~s}<0.01$ ). We observe that this finding is consistent with prospect theory's prediction of risk aversion for small probability losses, due to an overweighting of the small probability. Note that this is a behavioral effect that opposes underestimation of the small probability. We summarize our first result.

Result 1 We observe underestimation of the low-probability catastrophic risk; at the same time, we observe risk aversion in the insurance decisions, conditional on subjective probabilities.

\subsection{Social comparison}

We next consider the role of social comparison on insurance decisions. Our design allows us to study the effect of social comparison as laid out in Friedl et al. (2014): because of social reference points and loss aversion, insurance take-up is predicted to be higher when risks are uncorrelated then when risks are positively correlated. As Friedl et al. (2014) argue, in the case of positive correlation, there can be no social 
comparison losses, because other participants incur losses simultaneously. In the case of uncorrelated losses, the decision maker is either better off, or worse off than her peers. Because of loss aversion, the experience of losses receives more weight than the experience of gains, leading to higher demand for insurance to insulate against these social losses (thus implying higher WTPs and risk aversion in our context).

We assess the effect of independent versus correlated losses by studying insurance choices in the conditions with social information on losses, and with information on losses and choice, respectively. Table 1 shows average ${ }^{4}$ WTP for insurance contracts, as well as average measures for risk aversion (i.e., WTP-SEL) for independent and for positively correlated losses. For comparison, we include the respective values for the Individual Information condition as well. Although social comparison was salient for both social conditions, we do not observe any correlation-induced differences between insurance take-up in these comparisons. In unreported regressions, we further study the effect of correlated risks when controlling for the decision makers' gender and accounting for possible temporal effects. We find no evidence for peer effects in the initial rounds; neither do we observe that peer effects emerge over time.

Thus, in the current setting, it seems that there are no peer effects in insurance take-up. This might be due to a lack of social comparisons of the final outcomes made by the subjects; or it might be due to a low degree of social loss aversion despite salient social comparisons. Both the comparability with others and the degree of social loss feelings might be stronger in classroom settings with a low degree of anonymity as in the experiments of Friedl et al. (2014). Obviously, we would expect our anonymous laboratory setting to be a boundary condition for these effects: outside the laboratory people do often observe the outcomes of their peers, and consider them important for their own well-being. In any case, it is clear that this social comparison effect strongly depends on the details of the situation, and generalizations should only be made with much care. We summarize our second result.

Result 2 Insurance take-up is not affected by the correlation of risks across subjects.

The third aspect of decision making in our framework relates to the question of whether participants make efficient use of others' experiences. Especially for lowlikelihood risks, relying on their own experience only will lead people to base their decisions on small and potentially biased samples (e.g. Ert and Trautmann 2014). Using survey data, Viscusi and Zeckhauser (2015) provide evidence that people seem to strongly discount the information about contaminated water contained in other people's experiences. An important shortcoming in Viscusi and Zeckhauser's analyses is given by the fact that the authors do not observe whether people believe that the quality of their own tap water is correlated with the quality of the tap water of other people in their reference group. Indeed, water quality can strongly depend on local aspects, such as the quality and material of the pipes, etc. In our experiment, we can test their conjecture directly. It was clear to the participants that the unknown probability of the catastrophic loss was the same for all members of the five-person group, and thus, observed losses of other group members should directly be used to update the estimate of the underlying probability. Importantly, equal weight should be attached

\footnotetext{
${ }^{4}$ Average value per subject over all periods.
} 


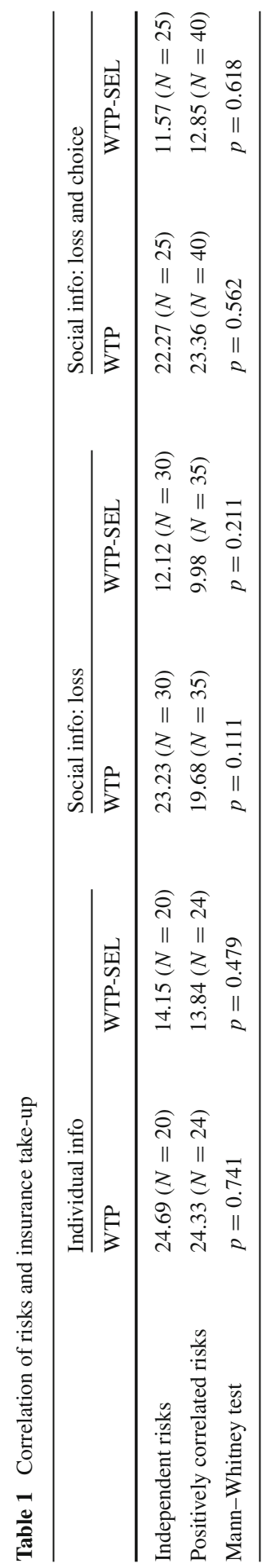


Table 2 Own experiences vs. others' experiences-effects of observed losses on probability estimates

\begin{tabular}{|c|c|c|c|c|}
\hline & \multicolumn{2}{|l|}{ Levels } & \multicolumn{2}{|l|}{ First difference } \\
\hline & $\begin{array}{l}\text { No period } \\
\text { controls }\end{array}$ & $\begin{array}{l}\text { Controlling } \\
\text { for period }\end{array}$ & $\begin{array}{l}\text { No period } \\
\text { controls }\end{array}$ & $\begin{array}{l}\text { Controlling } \\
\text { for period }\end{array}$ \\
\hline $\begin{array}{l}\text { Historical } \\
\text { frequency of } \\
\text { own losses }\end{array}$ & $0.052 * *$ & $0.052 * *$ & $0.028 * *$ & $0.028 * *$ \\
\hline $\begin{array}{l}\text { Historical } \\
\text { frequency of } \\
\text { others' losses (4 } \\
\text { people) }\end{array}$ & $0.091 * *$ & $0.091 * *$ & $0.050 * *$ & $0.050 * *$ \\
\hline $\begin{array}{l}F \text {-test testing own } \\
\quad=4 \text { others }^{a}\end{array}$ & $(<) p<0.01$ & $(<) p<0.01$ & $(=) p=0.277$ & $(=) p=0.277$ \\
\hline $\begin{array}{l}F \text {-test testing own } \\
\quad=1 \text { other }^{a}\end{array}$ & (>) $p<0.01$ & $(>) p<0.01$ & $(=) p=0.129$ & $(=) p=0.129$ \\
\hline
\end{tabular}

Entries are regression coefficients

$* * 1 \%$ significance level

${ }^{a}$ Size of own effect versus effect of other(s) indicated in parentheses

to an update based on a subject's own experience and an update based on another person's experience.

To study the impact of observed losses on probability estimates and insurance choice (i.e., WTPs), we run fixed effects panel regressions on levels and changes in the dependent variables, as a function of the observed losses. We restrict the analysis to the treatments with social information and uncorrelated risks. Table 2 reports regression coefficients for the analyses probability estimates, and Table 3 reports regression coefficients for insurance decisions (WTPs).

For the effect on probability estimates, we find that the historic frequency of losses based on the outcomes of other participants has a stronger effect than a person's own frequency of the past losses; this effect is significant only for levels and is nonsignificant for changes in the level (first differences). However, if we adjust for the fact that frequencies for the other people in the group are based on four observations for each single observation for the person's own experience, we find that own-experience-based updates are stronger than those based on another person's experience. For changes in frequencies, the effect points into the same direction, but does not reach statistical significance.

We can alternatively look directly at the effect on behavior, i.e., willingness to pay for insurance. Here, we find no significant differences between the effects of own experiences and the groups' experiences for either levels or differences. However, controlling again for the fact that others' experiences provide four times as many observations, we find significantly larger impact of the own experiences on insurance preferences (WTPs).

To summarize, we find evidence that people discount other people's information in their raw beliefs and in their insurance choices. A change in historical loss frequency based on a decision maker's own loss receives a much larger weight in her probability update and insurance decision than an equally large change based on other people's 
Table 3 Own experiences vs. others' experiences - effects of observed losses on insurance choices (WTPs)

\begin{tabular}{|c|c|c|c|c|}
\hline & \multicolumn{2}{|l|}{ Levels } & \multicolumn{2}{|l|}{ First differences } \\
\hline & $\begin{array}{l}\text { No period } \\
\text { controls }\end{array}$ & $\begin{array}{l}\text { Controlling } \\
\text { for period }\end{array}$ & $\begin{array}{l}\text { No period } \\
\text { controls }\end{array}$ & $\begin{array}{l}\text { Controlling } \\
\text { for period }\end{array}$ \\
\hline $\begin{array}{l}\text { Change in historical } \\
\text { frequency of own losses }\end{array}$ & $0.071 * *$ & $0.073 * *$ & $0.055^{*} *$ & $0.054 * *$ \\
\hline $\begin{array}{l}\text { Change in historical } \\
\text { frequency of others' } \\
\text { losses ( } 4 \text { people) }\end{array}$ & $0.081 * *$ & $0.086^{* *}$ & 0.017 & 0.017 \\
\hline $\begin{array}{l}F \text {-test testing own }=4 \\
\quad \text { others }^{a}\end{array}$ & $(=) p=0.765$ & $(=) p=0.678$ & $(=) p=0.398$ & (=) $p=0.391$ \\
\hline $\begin{array}{l}F \text {-test testing own }=1 \\
\text { other }^{a}\end{array}$ & $(>) p<0.01$ & $(>) p<0.01$ & $(>) p=0.029$ & $(>) p=0.028$ \\
\hline
\end{tabular}

Entries are regression coefficients

** $1 \%$ significance level

${ }^{a}$ Size of own effect versus effect of other(s) indicated in parentheses

experiences. In the current settings, this holds true despite both events being equally informative about the underlying event. We summarize our third result.

Result 3 Other people's experiences of low-likelihood catastrophic loss events are discounted in comparison with a person's own experience.

Both results 2 and 3 suggest that social comparison is weak: people disregard information on others' experiences, behavior, and outcomes. This is somewhat surprising in our setup, because we might expect that explicit and salient provision of information about others' outcomes and choices would lead to rather high degree of social comparison, compared to typical situations outside the lab. We probe the robustness of this result further by also looking at the direct effect of others' choices on own insurance choices. Such direct effects have been found in investment decisions (e.g., Bursztyn et al. 2014), and we would also expect them in the context of loss and insurance. Table 4 shows that the willingness to insure, as measured by the certainty equivalent, is not affected by information on others' insurance decisions. This holds true for the whole set of 40 periods, as well as for a restricted analyses based only on period 2 (i.e., exactly one instance of learning). The same is true for the actual percentages of insured subjects given the different information sets. Clearly, other participants' observed past insurance decisions had no effect on subjects' insurance decisions.

\section{Discussion and conclusions}

We set out to study behavioral aspects of insurance demand for low-probability catastrophic risk. The previous literature has suggested a set of behavioral patterns that may negatively influence insurance decisions. A first set of results relates to patterns of individual decision making. Here, we confirm the underestimation of low probabilities in a repeated-experience setting (Hertwig et al. 2004), and the finding of risk aversion for low-probability losses as predicted by the typical prospect theory parametrizations (e.g., Wakker 2010). 
Table 4 Imitating others' insurance choices?

\begin{tabular}{llllll}
\hline $\begin{array}{l}\text { \# Other group members } \\
\text { insured in preceding period }\end{array}$ & \multicolumn{2}{l}{ All periods } & & \multicolumn{2}{l}{ Only period 2 } \\
\cline { 2 - 3 } & WTP (mean) & Insured (\%) & & WTP (mean) & Insured (\%) \\
\hline 0 & 23.62 & 57.14 & & 20.5 & 46.15 \\
1 & 24.24 & 61.46 & & 24.76 & 61.11 \\
2 & 22.92 & 55.80 & & 24.72 & 62.96 \\
3 & 22.06 & 56.16 & & 21.5 & 50.00 \\
4 & 23.80 & 57.19 & & 19.1 & 60.00 \\
\hline
\end{tabular}

Based on data from Social Information: Loss and Choice condition only. Entries indicate behavior of those who observe others' decisions

The second set of findings refers to aspects of social comparison in insurance choices. The importance of social comparison for economic decisions has been widely acknowledged in the field (e.g., World Bank 2015), and recent research suggests that it may be central to insurance take-up as well. On the other hand, some authors have suggested that decision makers put too little weight on other people's relevant information (Viscusi and Zeckhauser 2015; see also Minson and Mueller 2012, for the case of groups exacerbating this effect). In our experiment, we are able to study these effects in one uniform design. In particular, in our study, the information regarding the other person is unambiguously relevant to the own insurance decision and highly salient for the decision maker. We do not find any effects of social information about experienced losses or choices on insurance take-up. The correlation of losses across people does not affect insurance take-up. In contrast, we confirm the discounting of information on other decision makers previously shown in field data: people do not update their beliefs (and behavior) equally strongly after the observation of a loss by another person compared to experiencing a loss themselves. This happens despite the fact that others' loss experiences are equally informative in our setting as their own loss experience.

Summarizing our results, we observe that the predicted individual decision-making patterns emerge robustly in the current setting. These patterns, therefore, suggest themselves as a firm basis for policy. In contrast, social effects on insurance choice seem to be less robust, depending more strongly on the respective setting. Although social influence effects occur to be less robust, they can often be substantial if they emerge (e.g., Trautmann and Vieider 2012, for a review), and may be relevant for policy interventions. Future research in the factors that drive social comparison effects is, therefore, warranted.

Open Access This article is distributed under the terms of the Creative Commons Attribution 4.0 International License (http://creativecommons.org/licenses/by/4.0/), which permits unrestricted use, distribution, and reproduction in any medium, provided you give appropriate credit to the original author(s) and the source, provide a link to the Creative Commons license, and indicate if changes were made. 


\section{Appendix}

\section{Instructions}

[In the first part, they will have to read an academic paper and assess its quality. It will take them some $40 \mathrm{~m}$ to read it. They will earn 80 PLN for their effort. They will get extra 10 if they can correctly guess whether the paper was published in a top econ journal or not published at all. I will only tell them at the very end, so that those losing 80 PLN will lose everything (they know they have). There will be no show-up fee.]

Part 2

In this experiment, you are a member of a five-person group. You start this experiment with 80 PLN you have earned in the previous part. This experiment will consist of 40 round.

In each round, you will face a chance of losing all your money. You will not be told the exact probability of this loss. It has been randomly selected from a range of 5-25\% (so that on average, the loss will take place not more often than once in 4 rounds but not less often than once in 20 rounds). The probability of the loss will remain the same throughout the experiment, and it is identical for every participant.

[Correlated Losses suffered in a given round by participants belonging to the same group are highly interdependent (correlated): if one participants makes a loss, probably some other members of the same group will make a loss as well.]

[Uncorrelated Losses suffered in a given round by participants belonging to the same group are independent (uncorrelated): whether or not one participants makes a loss does not affect the probability that other participants make a loss as well.]

One round will be selected at the end of the experiment and the outcome of this round will determine your final earnings. Non-selected rounds will become irrelevant. Each round will be selected with probability $1 / 40$.

In each round, you must estimate the probability of the loss and make a decision whether or not you wish to purchase insurance. Below each of these tasks will be described precisely, starting with the insurance decisions. One of these two tasks will be picked at random in the selected round to determine your earnings.

Task A: Insurance decision

In each round, you can protect yourself from the possible loss by purchasing insurance. If you are insured, you do not actually lose any money even if "the loss" takes place. To be insured, however, you have to pay for it. In each round, we will show you six different prices. For each of them, you will have to indicate whether you are willing to buy insurance for this round for such a price or not. You may accept all the offers or reject all the offers; you may also accept some offers only.

After you have made your decisions, we will pick one of these five offers at random. The decision you had indicated for this price level will become relevant for this round and will determine whether you buy insurance or not. Therefore, it pays to react to each offer in accordance with your true preference: "Yes" if given price is acceptable to you and "No" otherwise. At the end of the round, you will see whether you are purchasing insurance in this round (and, if so, at what price) or not and whether the 
loss occurs or not. These will determine your earnings (should this round be selected at the end of the experiment and within this round-the insurance decision).

[Social event You will also learn how many people in your group suffered a loss in this round.]

[Social event and choice You will also learn how many people in your group suffered a loss and how many were insured in this round.]

Please read the examples provided below (note that the decisions made by these hypothetical participants are for illustrative purposes only-you should not treat them as suggestions for your decisions).

Example 1 In round 22, participant Jan was shown these price levels: 5, 10, 14, 23, 29, and 37 PLN. He indicated that he was willing to pay 5 or 10 PLN, but not 14 or more for his insurance. The price level of 23 was subsequently randomly selected. Thus, his decision was "not insure". Then, Jan was told whether the loss takes place or not. Suppose it does. Then, Jan will know that if this round is selected for real payment at the end, he will end up with earnings of zero (he will indeed lose all his money). Suppose, now, there was no loss. Then, he will know that he will earn 80 PLN if his insurance decision from this round is selected for real payment. Upon receiving this information, Jan started the next round.

Example 2 In round 17, participant Anna was shown these price levels: 4, 9, 15, 22, 31 , and 39 PLN. She indicated that she was willing to pay 15 PLN or less, but not 22, 31 , or 39 for her insurance. The price level of 9 was subsequently randomly selected. Thus, her decision was "insure". If this round was selected for real payment, Anna would earn $80-9=71$ PLN, no matter whether loss takes place or not (still, she would be informed at the end of the round already whether there was a loss or not).

Task B: Estimation of the probability of the loss

On top of the insurance decisions, we shall also ask you in each round to estimate the probability of the loss. As mentioned, it can be any value within the range of 5$25 \%$. Because this probability is constant throughout the experiment, you may take into account in your estimations the occurrences of the loss in the previous rounds. Should your earnings be determined by your estimates of the probability that you have made in one of the rounds, you will receive the 80 PLN that you have started with less the penalty for imprecise estimation. This penalty is calculated as 4 PLN per pct. point you are off the target - the true value (this means that if the estimation task determines your earnings, it will become irrelevant whether or not you suffer a "loss" or are insured in any round.)

Example 3 In round five participant, Jan estimated the probability of the loss in any round at $9 \%$. Suppose in truth, the probability is $20 \%$. Should estimation made in this round be selected to determine Jan's earnings, it will be equal to $80-(20-9) \cdot 4=$ $80-44=36$ PLN.

Example 4 In round 36, participant Anna estimated the probability of the loss at $13 \%$. Suppose the true probability is $12 \%$. Should estimation made in this round be selected to determine Anna's earnings, it will be equal to $80-(13-12) \cdot 4=76$ PLN. 


\section{Details on the determination of insurance offer prices}

Each of the six prices offered in any given round was calculated as a sum of three components (rounded to the nearest zloty). The reference level was equal to $6,11,16$, 22, 31, and 41 PLN for the 1st, 2nd ... 6th price, respectively. The common random component was picked randomly once per round (i.e., it was identical for all the six prices) from the uniform distribution on $(-2,+2)$. The individual random component was uniformly distributed on $(-1,+1)$ and randomized independently for each price. This procedure generated some variability across rounds, which, one would hope, reduce subjects' boredom. The choice of specific reference levels was based on the quantiles of the distribution observed in a pilot study.

\section{References}

Botzen, W. J. W., \& van den Bergh, J. C. J. M. (2009). Bounded rationality, climate risks and insurance: Is there a market for natural disasters? Land Economics, 85, 266-279.

Botzen, W. J. W., \& van den Bergh, J. C. J. M. (2012). Risk attitudes to low-probability climate change risks: WTP for flood insurance. Journal of Economic Behavior and Organization, 82, 151-166.

Browne, M. J., Knoller, C., \& Richter, A. (2015). Behavioral bias and the demand for bicycle and flood insurance. Journal of Risk and Uncertainty, 50, 141-160.

Bursztyn, L., Ederer, F., Ferman, B., \& Yuchtman, N. (2014). Understanding mechanisms underlying peer effects: evidence from a field experiment on financial decisions. Econometrica, 82, 1273-1301.

Ert, E., \& Trautmann, S. T. (2014). Sampling experience reverses preferences for ambiguity. Journal of Risk and Uncertainty, 49, 31-42.

Fischbacher, U. (2007). Z-Tree: Zurich toolbox for ready-made economics experiments. Experimental Economics, 10, 171-178.

Friedl, A., de Miranda, K. L., \& Schmidt, U. (2014). Insurance demand and social comparison: an experimental analysis. Journal of Risk and Uncertainty, 48, 97-109.

Gallagher, J. (2014). Learning about an infrequent event: evidence from flood insurance take-up in the United States. American Economic Journal: Applied Economics, 6, 206-233.

Hertwig, R., Barron, G., Weber, E. U., \& Erev, I. (2004). Decisions from experience and the effect of rare events in risky choice. Psychological Science, 15(8), 534-539.

Huck, S., \& Weizsäcker, G. (2002). Do players correctly estimate what others do? Evidence of conservatism in beliefs. Journal of Economic Behavior and Organization, 47, 71-85.

Insurance Information Institute (2005). Flood Insurance: Facts \& Figures.

IPCC. (2012). Managing the risk of extreme events and disasters to advance climate change adaption: A special report of working groups I and II of the Intergovernmental Panel on Climate Change. Cambridge, UK: Cambridge University Press.

Kunreuther, H. C., Michel-Kerjan, E. O., Doherty, N. A., Grace, M. F., Klein, R. W., \& Pauly, M. V. (2009). At war with the weather: managing large-scale risks in a new era of catastrophes. Cambridge, MA: MIT Press.

Michel-Kerjan, E., \& Kunreuther, H. (2011). Redesigning flood insurance. Science, 333, 408-409.

Minson, J. S., \& Mueller, J. A. (2012). The cost of collaboration: why joint decision making exacerbates rejection of outside information. Psychological Science, 23, 219-224.

Page, L., Savage, D. A., \& Torgler, B. (2014). Variation in risk seeking behaviour following large losses: a natural experiment. European Economic Review, 71, 121-131.

Schade, C., Kunreuther, H., \& Koellinger, P. (2012). Protecting against low-probability disasters: the role of worry. Journal of Behavioral Decision Making, 25, 534-543.

Simon, H. A. (1955). A behavioral model of rational choice. Quarterly Journal of Economics, 69, 99-118.

Trautmann, S. T., \& van de Kuilen, G. (2015). Belief elicitation: a horse race among truth serums. Economic Journal, 125, 2116-2135.

Trautmann, S.T., \& Vieider, F.M. (2012). Social Influences on Risk Attitudes: Applications in Economics. In S. Roeser (ed.), Handbook of Risk Theory (Chapter 22, pp. 575-600), New York: Springer. 
Tversky, A., \& Kahneman, D. (1992). Advances in Prospect Theory: Cumulative Representation of Uncertainty. Journal of Risk and Uncertainty, 5, 297-323.

Viscusi, W. K., \& Zeckhauser, R. J. (2006). National survey evidence on disasters and relief: risk beliefs, self-interest, and compassion. Journal of Risk and Uncertainty, 33, 13-36.

Viscusi, W. K., \& Zeckhauser, R. J. (2015). The relative weights of direct and indirect experiences in the formation of environmental risk beliefs. Risk Analysis, 35, 318-331.

Wakker, P. P. (2010). Prospect theory: for risk and ambiguity. Cambridge, UK: Cambridge UniversityPress.

World Bank. (2015). World Development Report 2015: Mind, Society, and Behavior. Washington, DC: World Bank 